\title{
Three-dimensional double-network hydrogels of graphene oxide, alginate, and polyacrylonitrile for copper removal from aqueous solution
}

\author{
Jung-Weon Choi ${ }^{*}$, Hee Jin Kim*, Hayeon Ryu, Sanghwa Oh, Sang-June Choi ${ }^{\dagger}$ \\ School of Architectural, Civil, Environmental, and Energy Engineering, Kyungpook National University, Daegu 41566, Republic of Korea \\ "These authors contributed equally to this work.
}

\begin{abstract}
Three-dimensional (3D) double-network graphene oxide/alginate-polyacrylonitrile (GO/Ca-Alg2-PAN) composite hydrogels were synthesized via surface functionalization of GO to activate adsorption sites. The morphology and structure of the GO/Ca-Alg ${ }_{2}$-PAN were analyzed by scanning electron microscopy (SEM), Brunauer-Emmett-Teller (BET), Fourier transform infrared spectroscopy (FT-IR), and thermogravimetric analysis (TGA-DSC). The results of the physicochemical analyses indicated that GO/Ca-Alg2-PAN was successfully synthesized by the combination of a 2D-structured graphene oxide with the alginate which was functionalized with the PAN polymer to generate the 3D double network composites. This functionalization approach contributed to an increase in $\mathrm{Cu}^{2+}$ ion adsorption capacity. The maximum adsorption capacity of the $\mathrm{GO} / \mathrm{Ca}-\mathrm{Alg}_{2}-\mathrm{PAN}$ for $\mathrm{Cu}{ }^{2+}$ was $5.99 \mathrm{mmol} / \mathrm{g}$. The results of adsorption kinetic experiments indicated that the $\mathrm{GO} / \mathrm{Ca}-\mathrm{Alg}_{2}-\mathrm{PAN}$ reached adsorption equilibrium within $147 \mathrm{mins}$ at $2 \mathrm{mM} \mathrm{Cu}{ }^{2+}$ in accordance with a pseudo-second-order model.
\end{abstract}

Keywords: Adsorbent, Copper, Double network, Graphene oxide, Polymer, Wastewater

\section{Introduction}

As the industry develops, vast quantities of wastewater effluents are generated. These wastewaters contain a variety of heavy metal contaminants that need to be removed. Among these heavy metals, $\mathrm{Cu}^{2+}$ is an essential main target for removal, since it stimulates the central nervous system and causes cancer in human beings as well as affecting many ecosystems such as animals and plants in numerous adverse ways [1,2]. Up to now, there have been many studies on the removal of $\mathrm{Cu}^{2+}$ ions by various methods, including ion-exchange, extraction, precipitation, filtration etc. [3-6]. In contrast to adsorption, however, these methods are complex and relatively expensive.

Carbon-based materials are used as adsorbents in the field of water-treatment technology because of their abundance on earth and their high surface areas [7]. In particular, graphene has a two-dimensional (2D) structure with a high specific area and good stability $[7,8]$. Moreover, graphene oxide (GO) functionalized with many oxygen-containing groups has a high adsorption capacity for metal ions due to the binding of such ions to the surface; e.g. by crosslinking reactions with divalent cations such as calcium [9, 10]. However, GO is difficult to recover and separate from aqueous solution after treatment because of its high dispersibility, leading to environmental toxicity in aqueous solution.

Sodium alginate (Na-alginate) has been utilized for the encapsulation of GO. By encapsulating GO with Na-alginate, a single 2D GO network was combined with a single three-dimensional (3D) alginate network. Alginate consists of a linear chain of (1-4)-linked $\beta$-d-mannuronic acid and $\alpha$-l-guluronic acid [11]. Alginate can be transformed into a hydrogel by an ionic crosslinking method. The carboxyl group of $\alpha$-l-guluronic acid ionically bonds with divalent cations to form an "egg-box" structure [12]. In this study, calcium chloride was used as a divalent cation to transform the sodium alginate into calcium alginate $\left(\mathrm{Ca}-\mathrm{Alg}_{2}\right)$. When this alginate is combined with GO, the Ca cations are simultaneously linked with the alginate chains and the GO by a double crosslinking reaction to produce a $3 \mathrm{D}$ hydrogel double network [13-16]. The developed

Received October 28, 2019 Accepted December 13, 2019

${ }^{\dagger}$ Corresponding author

Email: sjchoi@knu.ac.kr

Tel: ++82-053-950-6582 Fax: +82-053-950-6579

Orchid: 0000-0002-9894-5955

Copyright (C) 2020 Korean Society of Environmental Engineers
Conted the original work is properly cited. 
hydrogels are excellent materials for separating and recovering ions from aqueous solution.

For the enhanced adsorption of $\mathrm{Cu}^{2+}$ ions, the surface of $\mathrm{GO} / \mathrm{Ca}-\mathrm{Alg}_{2}$ has been functionalized with a polymer that displays selectivity for $\mathrm{Cu}^{2+}$. Thiol-, amine- and nitrogen-containing functional groups are known to have strong binding properties to metal ions [17-19]. Among these functional groups, the amine group was selected for introduction onto the surface of the composites via functionalization with poly(acrylonitrile) (PAN) to faciliate removal of $\mathrm{Cu}^{2+}$ ions [20].

In the present study, adsorbents were synthesized using GO and alginate functionalized with polyacrylonitrile (namely, $\mathrm{GO} / \mathrm{Ca}-\mathrm{Alg}_{2}$-PAN) for the removal of $\mathrm{Cu}^{2+}$ from wastewater. The $\mathrm{GO} / \mathrm{Ca}-\mathrm{Alg}_{2}$-PAN adsorbents were characterized by field emission scanning electron microscopy (FE-SEM) with energy dispersive spectroscopy (EDS), specific surface area analysis, Fourier transform-infrared (FT-IR) spectroscopy, and thermogravimetric analysis (TGA). The batch adsorption and conditions such as the contact time were varied as parameters of adsorption experiments. Finally, we investigated whether these data were well-fitted to adsorption equilibrium isotherms and the pseudo-second-order kinetic models.

\section{Material and Methods}

\subsection{Materials and Reagents}

All of the chemicals were analytical-grade reagents and were used without further purification.

The graphene oxide (GO) sheets and copper(II) chloride dihydrate $\left(\mathrm{CuCl}_{2} \cdot 2 \mathrm{H}_{2} \mathrm{O}, 99.0 \%\right.$, average M.W. $\left.=170.48 \mathrm{~g} / \mathrm{mol}\right)$ were purchased from Sigma-Aldrich Chemical Co. The N,N-dimethylformamide $(\mathrm{DMF})\left(\mathrm{C}_{3} \mathrm{H}_{7} \mathrm{NO}, \mathrm{M} . \mathrm{W} .=73.09 \mathrm{~g} / \mathrm{mol}\right)$, calcium chloride $\left(\mathrm{CaCl}_{2}\right.$, $85 \%)$, and sodium alginate $\left(\mathrm{C}_{6} \mathrm{H}_{9} \mathrm{NaO}_{7}, \mathrm{M} . W .=216.121 \mathrm{~g} / \mathrm{mol}\right)$ were purchased from Daejung Chemicals \& Metals Co. (South Korea). The DMF was used for the polymerization of the acrylonitrile monomer to PAN. All of the solutions were prepared with ultra-pure water (18.2 MW $\times \mathrm{cm}$ ), which was obtained from Vivagen co. Ltd. (EXL5 Analysis 16, South Korea).

\subsection{Synthesis of the Sorbents}

The GO $(0.02 \mathrm{~g})$ was added to $20 \mathrm{~mL}$ of ultrapure water and dispersed completely using sonication (JAC-4020P, KODO Technical Research Co.) for $2 \mathrm{~h}$. Sodium alginate $(0.10 \mathrm{~g})$ was added into the ultrasonicated GO solution and completely dissolved by stirring, followed by ultrasonic irradiation. For functionalization with PAN, the acrylonitrile monomer was added and stirred for $2 \mathrm{~h}$ under an $\mathrm{N}_{2}$ atmosphere. After stirring, methanol was added in order to precipitate the slurry. To obtain a perfect solution by removing the homopolymer, the solution was washed several times with DMF. When a homogeneous solution was obtained, this was dropped into a $\mathrm{CaCl}_{2} \cdot 2 \mathrm{H}_{2} \mathrm{O}$ solution (10 g/L, $200 \mathrm{~mL}$ ) using a syringe pump (NE1000, 4science Co., USA) at $2 \mathrm{~mL} / \mathrm{min}$ under continuous magnetic stirring to encapsulate the alginate beads. The hydrogels were kept in $\mathrm{CaCl}_{2} \cdot 2 \mathrm{H}_{2} \mathrm{O}$ solution for stabilization, washed 2-3 times with ultrapure water, then placed in an oven and allowed to dry for $24 \mathrm{~h}$ for subsequent use as adsorbents.

\subsection{Characterization of the Sorbents}

The morphology of the sorbents was analyzed by FE-SEM (SU8220, Hitachi, Japan). The specific surface area, pore size, and pore volume were measured using a surface area and pore size analyzer (BET, Autosorb-IQ \& Quadrasorb SI, Quantachrome). The functional groups were analyzed to identify the chemical combination of sorbents by FT-IR (Frontier, PerkinElmer, USA). The thermal properties of the sorbents were identified via TGA (Q600, TA-Instrument, Japan) under an $\mathrm{N}_{2}$ atmosphere at a heating rate of $10^{\circ} \mathrm{C} / \mathrm{min}$.

\section{4. $\mathrm{Cu}^{2+}$ ion Adsorption Experiments}

As simulated wastewater, $\mathrm{Cu}^{2+}$ solutions were prepared with varying concentrations from 0.1 to $60 \mathrm{mM}$. All experiments were performed in a $50 \mathrm{~mL}$ conical tube (PE, SPL Korea) using a duplicate batch system. To carry out the adsorption isotherm experiments, $0.05 \mathrm{~g}$ of adsorbent was added into $55 \mathrm{~mL}$ of the $\mathrm{Cu}^{2+}$ solutions $(0.1,0.5,1.0,2.0,5.0,10,20,30,40,50$ and $60 \mathrm{mM})$ and was mixed at $250 \mathrm{rpm}$ for $24 \mathrm{~h}$ at room temperature. The samples were then centrifuged at $4,000 \mathrm{rpm}$ for $10 \mathrm{~min}$ to separate the sorbent from the solution. The solution was filtered using 0.20 $\mathrm{mm}$ nitrocellulose membrane filters (Whatman) before analysis.

Adsorption kinetic experiments were conducted by sampling at various time intervals after mixing the solutions containing 0.05 $\mathrm{g}$ of adsorbent and $55 \mathrm{~mL}$ of $2 \mathrm{mM} \mathrm{Cu}^{2+}$ in the tubes.

The supernatants were analyzed by inductively coupled plasma optical emission spectroscopy (ICP-OES, Optima 2100DV, PerkinElmer Co., USA) to measure the adsorption capacities. The equilibrium $\left(q_{e}\right)$ value is given by Eq. (1):

$$
q_{e}=\frac{\left(C_{o}-C_{e}\right) V}{m}
$$

where $q_{\mathrm{e}}$ is the $\mathrm{Cu}^{2+}$ adsorption capacity in milligrams per gram (mg/g) of adsorbent, $C_{\mathrm{o}}$ is the initial concentration of $\mathrm{Cu}^{2+}$ solution, $C_{\mathrm{e}}$ is the concentration of $\mathrm{Cu}^{2+}$ in the effluent solution after adsorption, $V$ is the solution contact volume $(\mathrm{mL})$, and $m$ is the mass of the adsorbent (g).

\section{Results and Discussion}

\subsection{Characterization of the Sorbents}

The FT-IR spectra of the GO, GO/Ca-Alg ${ }_{2}$, and GO/Ca-Alg 2 -PAN in the $4000-400 \mathrm{~cm}^{-1}$ region are presented in Fig. 1. Comparison of the spectra of GO (Fig. 1(a)) and GO/Ca-Alg (Fig. 1(b)) reveals the appearance of four new bands at $1453 \mathrm{~cm}^{-1}, 1358 \mathrm{~cm}^{-1}, 1249$ $\mathrm{cm}^{-1}$, and $1074 \mathrm{~cm}^{-1}$, which indicate that the graphene oxide was fully reacted with the calcium alginate during the preparation of the double-network composite [21]. The presence of the - $\mathrm{COO}$ stretching vibrations and the $\mathrm{C}-\mathrm{H}$ stretching bands located at 1453 and $1074 \mathrm{~cm}^{-1}$, the $\mathrm{C}-\mathrm{OH}$ bending band at $1357 \mathrm{~cm}^{-1}$, the $\mathrm{C}-\mathrm{O}-\mathrm{C}$ asymmetric stretching band at $1249 \mathrm{~cm}^{-1}$ was observed [22]. An additional new band in the spectrum of GO/Ca-Alg $2-\mathrm{PAN}$ (Fig. 1(c)) indicates the successful combination of poly(acrylonitrile). Normally, nitrile-containing compounds have a sharp adsorption in the region of $2260-2200 \mathrm{~cm}^{-1}[23,24]$. The results of the 


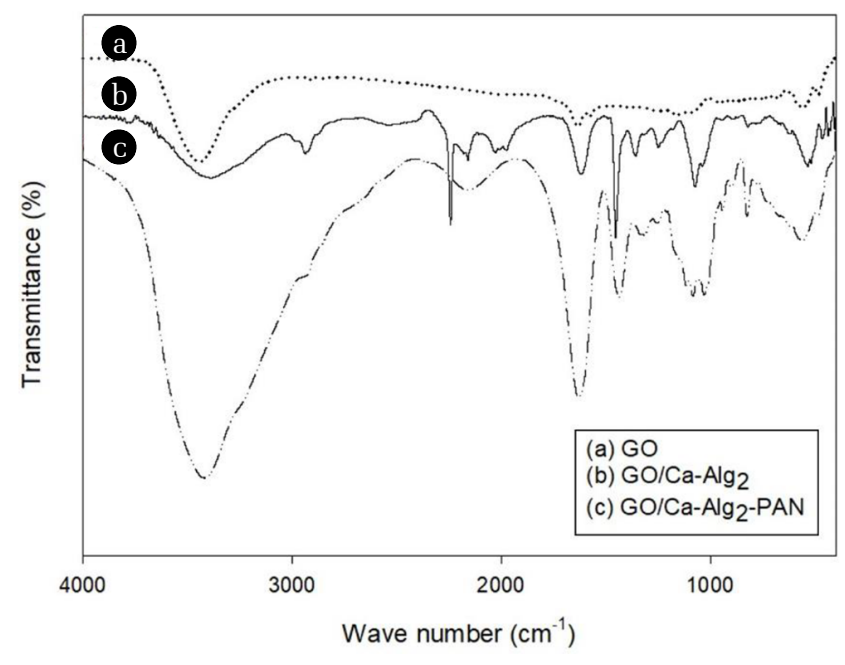

Fig. 1. FT-IR spectra of (a) $\mathrm{GO}$, (b) $\mathrm{GO} / \mathrm{Ca}-\mathrm{Alg}_{2}$, and (c) $\mathrm{GO} / \mathrm{Ca}-\mathrm{Alg}_{2}-\mathrm{PAN}$.

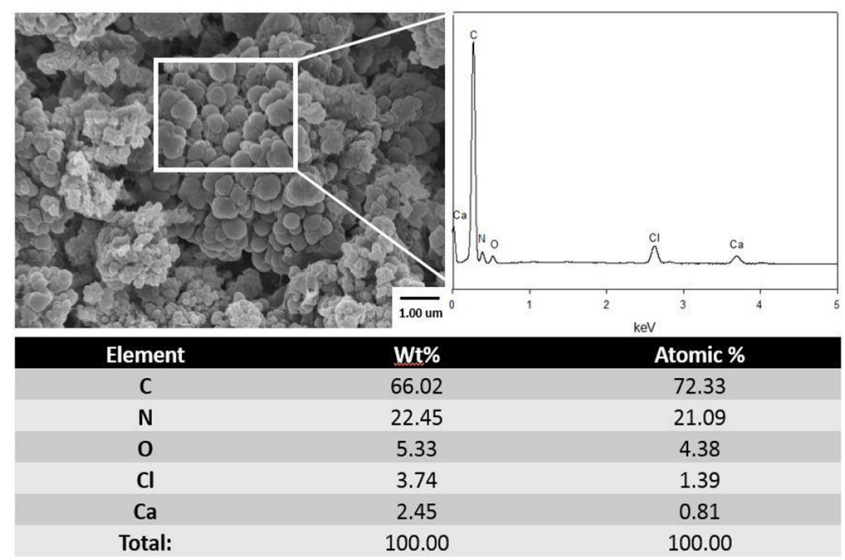

Fig. 2. SEM-EDS spectra of GO/Ca-Alg 2 PAN beads.

spectral analysis of functional groups thus confirmed that the double-network 3D complex GO/Ca- $\mathrm{Alg}_{2}$-PAN was successfully synthesized.

The qualitative EDS results for the GO/Ca- $\mathrm{Alg}_{2}$-PAN showed the presence of $\mathrm{C}, \mathrm{N}, \mathrm{O}, \mathrm{Ca}$ and $\mathrm{Cl}$, as anticipated (Fig. 2). The presence of $\mathrm{Ca}$ and $\mathrm{Cl}$ in the $\mathrm{Ca}-\mathrm{Alg}_{2}$ beads, along with $\mathrm{C}$ and $\mathrm{O}$ in the GO and PAN, demonstrate that the synthesized $\mathrm{GO} / \mathrm{Ca}-\mathrm{Alg}_{2}$-PAN beads have sufficient adsorption sites. In addition, the transformation of Na-Alg to $\mathrm{Ca}-\mathrm{Alg}_{2}$ was achieved by cation-exchange as the beads formed the "egg-box" structure [13].

The surface structures of the GO/Ca-Alg 2 -PAN were investigated by analysis of the physical properties and FE-SEM images presented in Fig. 3. The FE-SEM image in Fig. 3(a) indicates that the GO consists of $2 \mathrm{D}$ plates, while Fig. 3(b) indicates the 3D structure of the GO/Ca-Alg ${ }_{2}$ beads after transformation of the GO/Na-Alg solution. The GO/Ca-Alg 2 -PAN composites are imaged in Fig. 3(c-d), which shows a group of spheres onto which the 3D-structured polymer was functionalized. The surface area of $\mathrm{GO}$ is much greater than those of GO/Ca-Alg 2 and GO/Ca-Alg 2 -PAN; hence, the surface area of the GO/Ca- $\mathrm{Alg}_{2}$ is dramatically reduced to $2.466 \mathrm{~m}^{2}$ per gram of alginate. However, the functionalization of GO/Ca-Alg 2

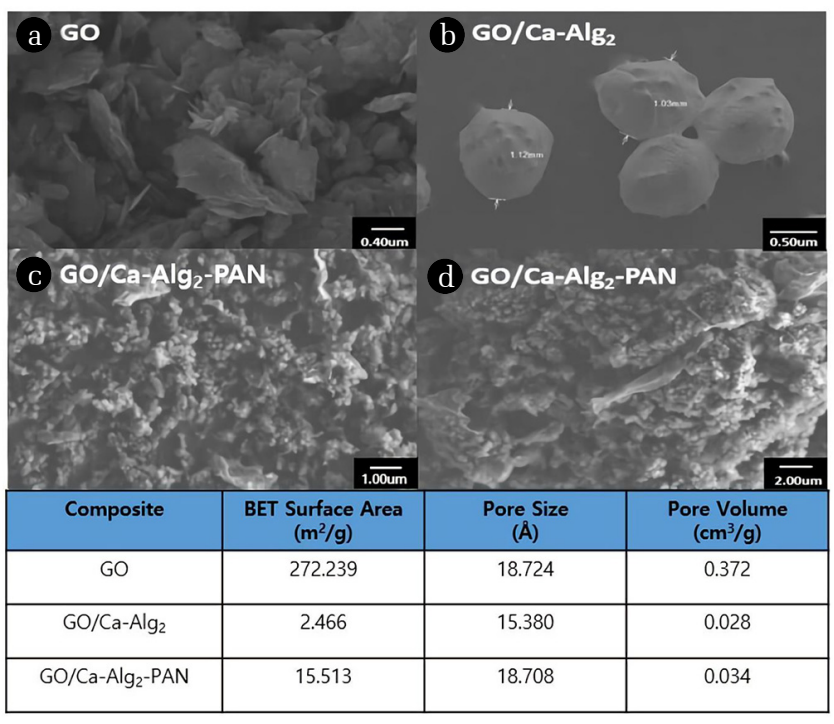

Fig. 3. FE-SEM images and physical properties of (a) GO, (b) GO/Ca-Alg and (c-d) GO/Ca-Alg - PAN beads.

with PAN to form GO/Ca-Alg 2 -PAN with the double interpenetrating polymer network (IPN) structure led to an increase in surface area. The pore-sizes were similar, while the pore volume of GO was the largest. The final composition, GO/Ca- $\mathrm{Alg}_{2}-\mathrm{PAN}$, had a pore volume of $0.034 \mathrm{~cm}^{3} / \mathrm{g}$. The smaller surface area and pore volume relative to GO were due to the presence of alginate, but the resulting beads are easily separated from aqueous solution and have the advantage of high efficiency for a low surface area. [25]. As shown in Fig. 3, the PAN polymer was successfully functionalized onto the GO/Ca- $\mathrm{Alg}_{2}$ hydrogel-forming 3D structure.

\subsection{Adsorption Isotherm and Kinetics}

The data obtained from the $\mathrm{Cu}^{2+}$ adsorption experiment were fitted using two equilibrium models to confirm the adsorption behavior. The Langmuir isotherm model represents the monolayer adsorption of metal ions in accordance with Eq. (2):

$$
q_{e}=\frac{q_{m} b C_{e}}{1+b C_{e}}
$$

where $q_{\mathrm{m}}(\mathrm{mmol} / \mathrm{g})$ is the maximum sorption capacity, $b(\mathrm{~L} / \mathrm{mmol})$ is the Langmuir adsorption constant related to the free energy of the sorption, and $C_{e}$ is the equilibrium concentration of $\mathrm{Cu}^{2+}$ aqueous solution.

Alternatively, multiple-layer adsorption can be analyzed according to the Freundlich adsorption model given by Eq. (3):

$$
q_{e}=K_{f} C_{e}^{1 / n}
$$

where $K_{\mathrm{f}}\left[(\mathrm{mmol} / \mathrm{g})(\mathrm{L} / \mathrm{mmol})^{1 / \mathrm{n}}\right]$ and $\mathrm{n}$ are constants of the Freundlich model.

The kinetic behavior of $\mathrm{Cu}^{2+}$ adsorption was fitted using Lagergren's pseudo first-order and pseudo second-order models, Eqs. (4) and (5), respectively: 


$$
\begin{gathered}
\ln \left(q_{e}-q_{t}\right)=\ln q_{e}-k_{1} t \\
\frac{t}{q_{t}}=\frac{1}{k_{2} q_{e}^{2}}+\frac{t}{q_{e}}
\end{gathered}
$$

where $q_{\mathrm{t}}$ is the concentration of $\mathrm{Cu}^{2+}$ ions $(\mathrm{mmol} / \mathrm{g})$ at time $(\mathrm{t})$, $q_{\mathrm{e}}$ is the equilibrium concentration, $k_{1}$ is the pseudo-first-order constant $\left(\mathrm{min}^{-1}\right)$ and $k_{2}$ is the pseudo-second-order constant (g/mmol/min).

From the pseudo second-order model, the initial adsorption rate (h) could be calculated according to Eq. (6):

$$
h=k_{2} q_{e}^{2}
$$

Fig. 4 shows the equilibrium isotherm nonlinear models and kinetic models for the removal of $\mathrm{Cu}^{2+}$ at room temperature. In the Langmuir isotherm model, the maximum adsorption capacity $\left(q_{\mathrm{m}}\right)$ value of the GO/Ca-Alg${ }_{2}-\mathrm{PAN}$ is $5.99 \mathrm{mmol} / \mathrm{g}$. In the Freundlich model, however, the maximum adsorption amount increased with increasing concentration in solution. In Fig. 4(a), both kinetic models were well-fitted to the experimental data.

The constants and correlation coefficients of the isotherm and kinetic models are indicated in Table 1. When fitting the two adsorption models with the experimental data, the Freundlich isotherm model gave a better fit than the Langmuir isotherm model. In the Freundlich isotherm model, the determination coefficient $\left(r^{2}\right)$ was 0.980, which is closer to 1 . Since the Freundlich model is well-suited

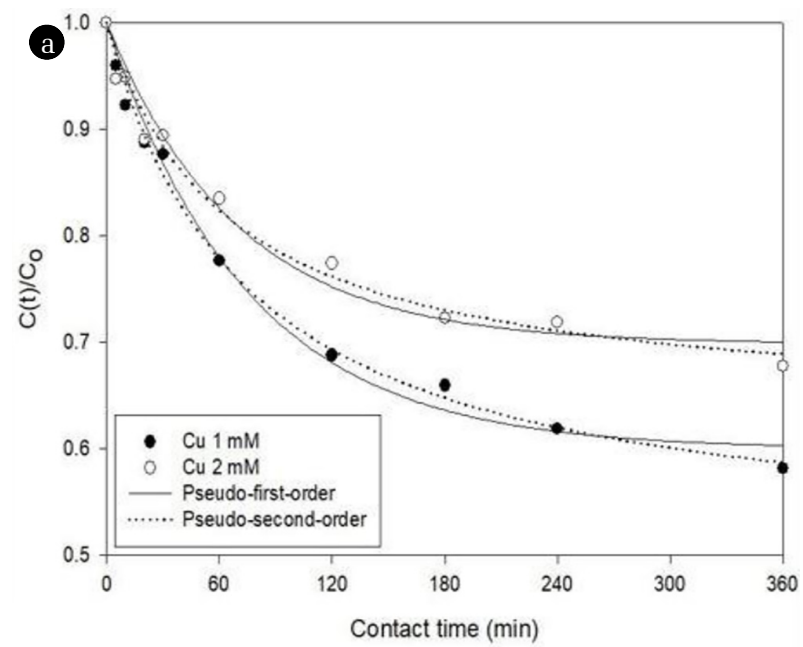

to modeling $\mathrm{Cu}^{2+}$ removal using GO/Ca- $\mathrm{Alg}_{2}$-PAN, we conclude that the synthesized $\mathrm{GO} / \mathrm{Ca}-\mathrm{Alg}_{2}-\mathrm{PAN}$ is a double-network capable of adsorbing multiple layers of $\mathrm{Cu}^{2+}$ at multiple adsorption sites. In the absorption kinetics results, the kinetic behavior of the $\mathrm{GO} / \mathrm{Ca}-\mathrm{Alg}_{2}$-PAN depended on the second-order model better than the first-order model through the $r^{2}$ value of two kinetic models for the absorption of $1 \mathrm{mM}$ and $2 \mathrm{mM}$ of $\mathrm{Cu}^{2+}$. According to the pseudo first-order model, the equilibrium of adsorption was achieved within about 120 mins. Normally, powdered adsorbents reach equilibrium in a minimum of 10 mins [26]. However, the beads require time to swell in aqueous solution, so stirring for extra time was considered in order to reach equilibrium. As a result, the isotherm adsorption experiments in the present study confirmed that a stirring-time of $24 \mathrm{~h}$ allowed sufficient contact time for equilibrium to be reached. In addition, for the pseudo second-order model, the $\mathrm{h}$ value and the $q_{e}$ value increase as the concentration of $\mathrm{Cu}^{2+}$ increases. Hence, as the concentration increases, the time to reach the adsorption equilibrium decreases and the amount absorbed increases.

Generally, the mechanism of adsorption consists of three steps, namely: (i) external mass transfer, (ii) particle pore diffusion, and (ii) adsorption reaction at a surface site [27]. It can be interpreted according to two equations relating to the intraparticle diffusion [28] and the external mass transfer rate [29]. The rate of intraparticle diffusion equation is given by Eq. (7):

$$
q_{t}=k_{i} t^{0.5}
$$

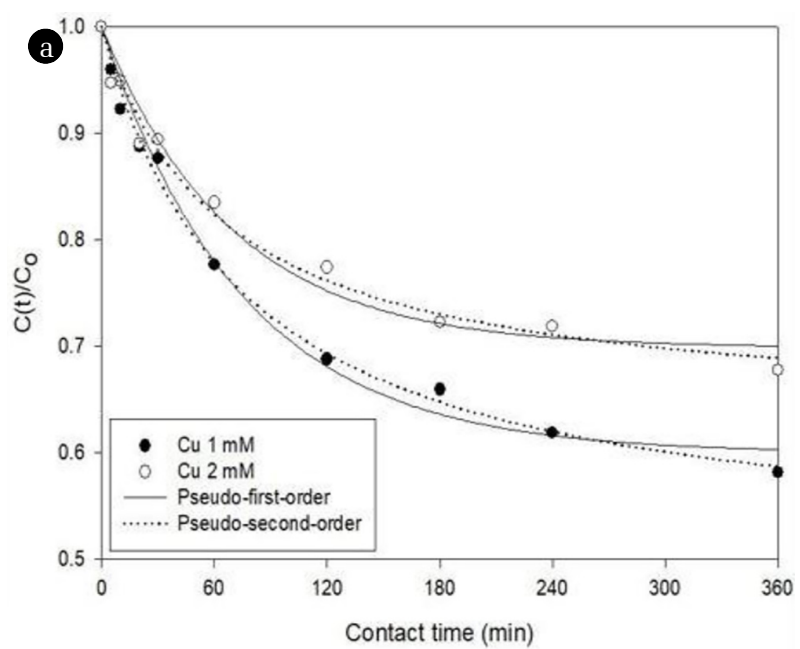

Fig. 4. Adsorption (a) Isotherms and (b) Kinetic models of $\mathrm{Cu}^{2+}$ using $\mathrm{GO} / \mathrm{Ca}-\mathrm{Alg}_{2}-\mathrm{PAN}$.

Table 1. Constants and Correlation Coefficients of Isotherm Models for $\mathrm{Cu}^{2+}$ Removal at 0.1-60 $\mathrm{mM}$ and Kinetic Models at 1 and $2 \mathrm{mM} \mathrm{Cu}^{2+}$

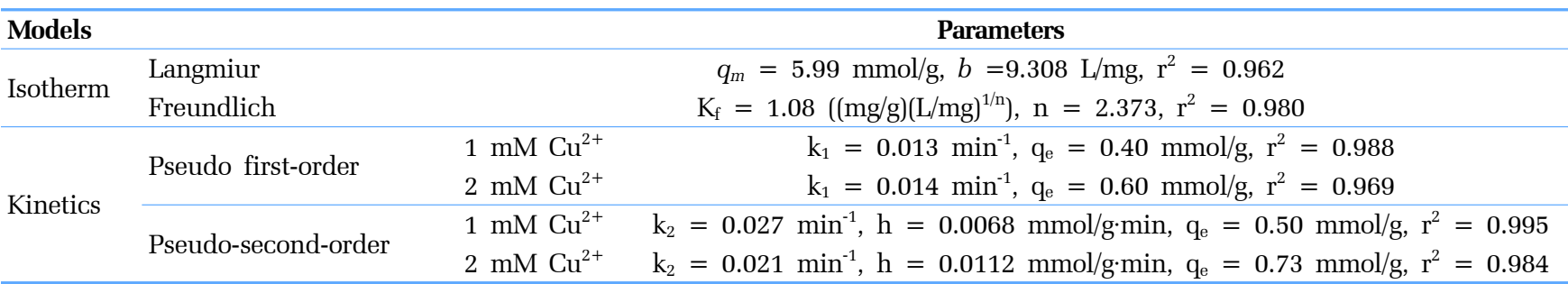


Table 2. Kinetic Data Calculated for the Adsorption of $1 \mathrm{mM}$ and $2 \mathrm{mM} \mathrm{Cu}{ }^{2+}$ by GO/Ca-Alg $2-\mathrm{PAN}$

\begin{tabular}{|c|c|c|c|c|c|c|c|}
\hline \multirow{2}{*}{$\mathrm{Cu}^{2+}(\mathrm{mM})$} & \multicolumn{5}{|c|}{ Intraparticle } & \multicolumn{2}{|c|}{ External } \\
\hline & $\mathbf{k}_{\mathrm{i}, 1}\left(\mathrm{mmol} / \mathrm{g} \cdot \min ^{0.5}\right)$ & $\mathbf{k}_{\mathrm{i}, 2}\left(\mathbf{m m o l} / \mathrm{g} \cdot \min ^{0.5}\right)$ & $D \times 10^{9}\left(\mathrm{~m}^{2} / \mathrm{s}\right)$ & $\mathbf{r}_{1}^{2}$ & $\mathbf{r}_{2}^{2}$ & $k_{s} \times 10^{8}(\mathrm{~m} / \mathrm{s})$ & $\mathbf{r}^{2}$ \\
\hline 1 & 0.026 & 0.013 & 3.8034 & 0.977 & 0.973 & 12.2478 & 0.759 \\
\hline 2 & 0.039 & 0.016 & 2.5563 & 0.969 & 0.912 & 9.0247 & 0.691 \\
\hline
\end{tabular}

where $k_{i}$ is an intraparticle diffusion rate constant $\left(\mathrm{mmol} / \mathrm{g} \cdot \mathrm{min}^{0.5}\right)$, $t$ is the contact time (min) and $q_{t}$ is the intraparticle diffusion rate.

From this, the diffusion coefficient $\left(D, \mathrm{~m}^{2} / \mathrm{s}\right)$ is calculated using Eq. (8):

$$
\mathrm{D}=\frac{0.03}{t_{1 / 2}} d^{2}
$$

where $t_{1 / 2}$ is the time when the adsorption reaches one half of the equilibrium value and $d$ is the diameter of the adsorbents (m).

The external mass transfer rate can be represented by Eq. (9):

$$
-\ln \frac{C(t)}{C_{o}}=k_{s} \frac{A}{V} t
$$

where $A$ is the surface area of adsorbents $\left(\mathrm{m}^{2}\right), V$ is the volume of solution $\left(\mathrm{m}^{3}\right)$, and the mass transfer coefficient $k_{\mathrm{s}}\left(\mathrm{m}^{2} / \mathrm{min}\right)$ can be determined experimentally from a plot of $-\ln \left(C(t) / C_{o}\right)$ against $t$.

As indicated in Fig. 5, multilinearities were observed in the plots of $q_{t}$ versus $t_{0.5}$ for 1 and $2 \mathrm{mM} \mathrm{Cu}^{2+}$. The graph is divided into two linear lines, indicating that the $\mathrm{Cu}^{2+}$ adsorption takes place in a complex process involving external mass transfer and intraparticle diffusion. The steep slope in the first step indicates the external mass transfer to the external surface, and the second shallower slope is due to the intraparticle diffusion [30, 31]. The parameters from the Figures are presented in Table 2. The $k_{i, 1}$ and $k_{i, 2}$ values were calculated from the two straight lines in Fig. 5 , each of which has a high correlation value $\left(r^{2}\right)$ of 0.9 or more. Although the adsorption rate was higher for a $\mathrm{Cu}^{2+}$ concentration of $2 \mathrm{mM}$ than for $1 \mathrm{mM}$, the values of $D$ and $k_{s}$ of the external

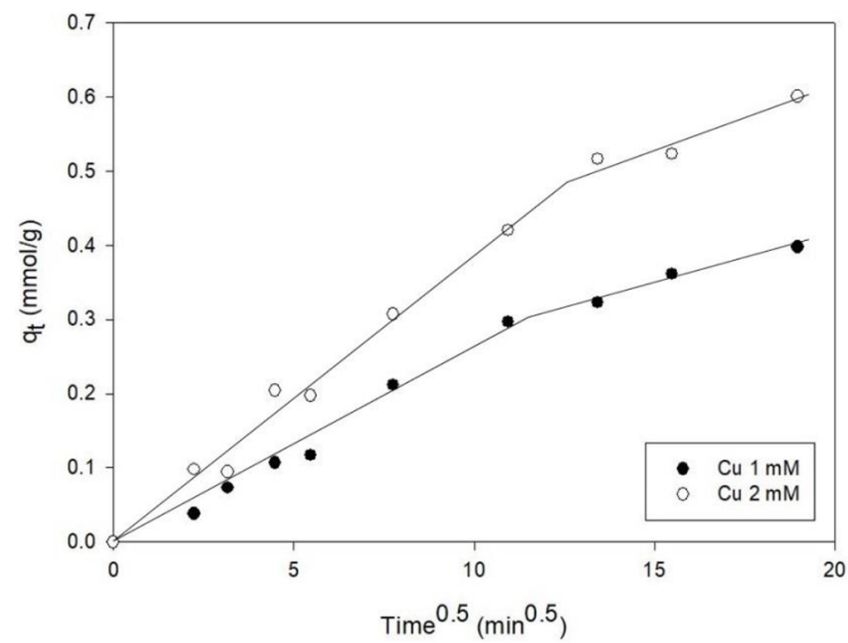

Fig. 5. Intraparticle diffusion plot for $\mathrm{Cu}^{2+}$ adsorption by $\mathrm{GO} / \mathrm{Ca}-\mathrm{Alg}_{2}-\mathrm{PAN}$. material were decreased. This is because the adsorption rate is fast but takes a relatively long time to reach the adsorption equilibrium. These results confirm that the adsorption occurs by both internal diffusion and external mass transfer. With $1 \mathrm{mM}$ $\mathrm{Cu}^{2+}$, the $D$ value of the intraparticle diffusion is $3.8034 \times 10^{9}$ and the $k_{s}$ value of the external mass transfer is 12.2478 . For 2 $\mathrm{mM} \mathrm{Cu}{ }^{2+}$, the corresponding values are $2.5563 \times 10^{9} \mathrm{~m}^{2} / \mathrm{s}$ and $9.0247 \times 10^{8} \mathrm{~m} / \mathrm{s}$, respectively. Therefore, intraparticle diffusion relatively dominates the total adsorption process.

\section{Conclusions}

In this study, the 3D structured double-network composites $\mathrm{GO} / \mathrm{Ca}-\mathrm{Alg}_{2}$-PAN were developed for removing $\mathrm{Cu}^{2+}$ ions from aqueous solution. The successful synthesis of $\mathrm{GO} / \mathrm{Ca}-\mathrm{Alg}_{2}-\mathrm{PAN}$ was confirmed by various physicochemical analyses. The synthesized $\mathrm{GO} / \mathrm{Ca}-\mathrm{Alg}_{2}-\mathrm{PAN}$ is robust and has a 3D double-network structure with many adsorption sites for $\mathrm{Cu}^{2+}$ ions. The GO/Ca- $\mathrm{Alg}_{2}-\mathrm{PAN}$ adsorbed $\mathrm{Cu}^{2+}$ ions with a maximum sorption capacity of 5.998 $\mathrm{mmol} / \mathrm{g}$. The adsorption behavior of the GO/Ca- $\mathrm{Alg}_{2}-\mathrm{PAN}$ was well-fitted to the Freundlich isotherm model in the batch experiments. The adsorption equilibrium of $\mathrm{GO} / \mathrm{Ca}-\mathrm{Alg}_{2}-\mathrm{PAN}$ was reached within 147 mins. Therefore, the GO/Ca-Alg 2 -PAN is judged to be an efficient adsorbent for $\mathrm{Cu}^{2+}$ ion removal from wastewater.

\section{Acknowledgment}

This research was supported by the Nuclear Energy Development Program through the National Research Foundation of Korea (NRF), funded by the Ministry of Science and ICT (2018M2B2B1065631).

\section{Author Contributions}

J.W.C. (ph.D. student) conducted all the experiments. H.J.K. (Doctor) wrote most of the manuscipts. H.R. (Master) did a little analysis. S.w.O. (Professor) helped revised the manuscript. S.-J.C. (Professor) led the overall study as a corresponding author.

\section{References}

1. Li N, Bai R. Copper adsorption on chitosan-cellulose hydrogel beads: behaviors and mechanisms. Sep. Purif. Technol. 2005;42:237-247.

2. Larous S, Meniai A-H, Lehocine MB. Experimental study of the removal of copper from aqueous solutions by adsorption using sawdust. Desalination 2005;185:483-490. 
3. Barros GKGC, Melo RPF, de Barros Neto EL. Removal of copper ions using sodium hexadecanoate by ionic flocculation. Sep. Purif. Technol. 2018;200:294-299.

4. Larsson M, Nosrati A, Kaur S, Wagner J, Baus U, Nydén M. Copper removal from acid mine drainage-polluted water using glutaraldehyde-polyethyleneimine modified diatomaceous earth particles. Heliyon 2018;4:e00520.

5. Thanh DN, Novák P, Vejpravova J, Vu HN, Lederer J, Munshi T. Removal of copper and nickel from water using nanocomposite of magnetic hydroxyapatite nanorods. J. Magn. Magn. Mater. 2018;456:451-460.

6. Jang J, Lee DS. Magnetic Prussian blue nanocomposites for effective cesium removal from aqueous solution. Ind. Eng. Chem. Res. 2016;55:3852-3860.

7. Vu HC, Dwivedi AD, Le TT, Seo S-H, Kim E-J, Chang Y-S. Magnetite graphene oxide encapsulated in alginate beads for enhanced adsorption of $\mathrm{Cr}(\mathrm{VI})$ and As (V) from aqueous solutions: Role of crosslinking metal cations in $\mathrm{pH}$ control. Chem. Eng. J. 2017;307:220-229.

8. Hosseinzadeh H, Ramin S. Effective removal of copper from aqueous solutions by modified magnetic chitosan/graphene oxide nanocomposites. Int. J. Biol. Macromol. 2018;113:859-868.

9. Serrano-Aroca A, Deb S. Synthesis of irregular graphene oxide tubes using green chemistry and their potential use as reinforcement materials for biomedical applications. PloS one. 2017;12:e0185235.

10. Zhu Y, Murali S, Cai W, et al. Graphene and graphene oxide: synthesis, properties, and applications. J. Adv. Mater. 2010;22:3906-3924.

11. Zhuang Y, Yu F, Chen J, Ma J. Batch and column adsorption of methylene blue by graphene/alginate nanocomposite: Comparison of single-network and double-network hydrogels. Journal of environmental chemical engineering. 2016;4:147-156.

12. Sikorski P, Mo F, Skjåk-Bræk G, Stokke BT. Evidence for egg-box-compatible interactions in calcium-alginate gels from fiber X-ray diffraction. Biomacromolecules. 2007;8:2098-2103.

13. Gong JP, Katsuyama Y, Kurokawa T, Osada Y. Double-network hydrogels with extremely high mechanical strength. Advanced materials. 2003;15:1155-1158.

14. Haque MA, Kurokawa T, Gong JP. Super tough double network hydrogels and their application as biomaterials. Polymer 2012;53:1805-1822.

15. Serrano-Aroca Á, Ruiz-Pividal J-F, Llorens-Gámez M. Enhancement of water diffusion and compression performance of crosslinked alginate films with a minuscule amount of graphene oxide. Sci. Rep. 2017;7:11684.

16. Llorens-Gámez M, Serrano-Aroca Á. Low-cost advanced hydrogels of calcium alginate/carbon nanofibers with enhanced water diffusion and compression properties. Polymers 2018;10:405.

17. Yoshitake H, Yokoi T, Tatsumi T. Adsorption of chromate and arsenate by amino-functionalized MCM-41 and SBA-1. Chem. Mater. 2002;14:4603-4610.

18. Nastasović A, Jovanović S, Đorđević D, Onjia A, Jakovljević D, Novaković T. Metal sorption on macroporous poly (GMA-co-EGDMA) modified with ethylenediamine. React. Func. Polymer. 2004;58:139-147.

19. Deng S, Bai R. Removal of trivalent and hexavalent chromium with aminated polyacrylonitrile fibers: performance and mechanisms. Water Res. 2004;38:2424-2432.

20. Deng S, Bai R, Chen JP. Aminated polyacrylonitrile fibers for lead and copper removal. Langmuir 2003;19:5058-5064.

21. Platero E, Fernandez ME, Bonelli PR, Cukierman AL. Graphene oxide/alginate beads as adsorbents: Influence of the load and the drying method on their physicochemical-mechanical properties and adsorptive performance. J. Colloid Interface Sci. 2017;491:1-12.

22. Gupta A, Paliwal D, Bajaj P. Effect of an acidic comonomer on thermooxidative stabilization of polyacrylonitrile. J. Appl. Polymer Sci. 1995;58:1161-1174.

23. Usami T, Itoh T, Ohtani H, Tsuge S. Structural study of polyacrylonitrile fibers during oxidative thermal degradation by pyrolysis-gas chromatography, solid-state carbon-13 NMR, and Fourier-transform infrared spectroscopy. Macromol. 1990;23: 2460-2465.

24. Uddin ME, Layek RK, Kim NH, Hui D, Lee JH. Preparation and properties of reduced graphene oxide/polyacrylonitrile nanocomposites using polyvinyl phenol. Composit. B: Eng. 2015;80:238-245.

25. Ngah WSW, Fatinathan S. Adsorption of Cu(II) ions in aqueous solution using chitosan beads, chitosan-GLA beads and chitosan-alginate beads. Chem. Eng. J. 2008;143:62-72.

26. Lee HK, Yang DS, Oh W, Choi S-J. Copper Ferrocyanide Functionalized Core-Shell Magnetic Silica Composites for the Selective Removal of Cesium Ions from Radioactive Liquid Waste. J. Nanosci. Nanotechnol. 2016;16:6223-6230.

27. Cheung WH, Szeto YS, McKay G. Intraparticle diffusion processes during acid dye adsorption onto chitosan. Bioresour. Technol. 2007;98:2897-2904.

28. Krishna R. A unified approach to the modelling of intraparticle diffusion in adsorption processes. Gas Sep. Purif. 1993;7:91-104.

29. Mathews A, Weber W, editors. Effects of external mass transfer and intraparticle diffusion on adsorption rates in slurry reactors. AIChE Symposium Series; 1977.

30. Chen D, Zhang J, Chen J. Adsorption of methyl tert-butyl ether using granular activated carbon: Equilibrium and kinetic analysis. Int. J. Environ. Sci. Technol. 2010;7:235-242.

31. Depci T, Kul AR, Önal Y. Competitive adsorption of lead and zinc from aqueous solution on activated carbon prepared from Van apple pulp: Study in single-and multi-solute systems. Chem. Eng. J. 2012;200:224-236. 